\title{
Genetic diversity of sorghum (Sorghum bicolor (L) Moench) accessions from thirteen regions of Burkina Faso
}

\section{S. Zara NIKIEMA ${ }^{1 *}$, Jacob SANOU ${ }^{1}$, Banse OUEDRAOGO ${ }^{1}$, Vernon GRACEN ${ }^{2}$, B. Pangirayi TONGOONA ${ }^{3}$ and Samuel Offei KWAME}

${ }^{1}$ Institute of Environment and Researches in Agriculture (INERA), BP 910 Bobo Dioulasso, Burkina Faso

${ }^{2}$ Departments of Plant Breeding and Genetics, 520 Bradfield Hall, Cornell University, Ithaca, NY 14850, USA.

${ }^{3}$ West Africa Centre for Crop Improvement (WACCI), University of Ghana, BMP 30, Legon, Accra, Ghana. * Corresponding author; E-mail: zaran0150@gmail.com ; Tel: +22672101522/+22657138968

\begin{abstract}
Sorghum (Sorghum bicolor (L.) Moench) is a staple food crop for West African countries in general and Burkina Faso in particular. It is mainly grown by small holder farmers for their livelihoods. They grow their landraces which is a mixture of more than two varieties. Unfortunately, the yields of farmer varieties are low compared to improved ones bred by sorghum breeders with the potential up to $3 \mathrm{t} / \mathrm{ha}$. The objective of the study was to identify the genetic diversity between improved varieties released by research institutions and farmer accessions at the molecular level. DNA sample were collected from hundred and twenty-three accessions collected from thirteen regions of Burkina Faso. DNA samples were successfully genotyped using a multiplexed complex of 28 microsatellites DNA markers for 110 genotypes. The sorghum genotypes comprised of Guinea, Caudatum and Guinea-Caudatum races. Farmer varieties were defined mainly in Guinea and Guinea-Caudatum races while the improved varieties were mainly Caudatum races. The inbreeding level FIS (the inbreeding level within a given population) for each group improved, farmer varieties varied between $-1<$ FIS $>1$. This shows the autogenous nature of sorghum varieties. Breeding schemes can therefore be designed for improvement of farmer preferred varieties.
\end{abstract}

(C) 2020 International Formulae Group. All rights reserved.

Keywords: Sorghum Microsatellites, Guinea, Caudatum, Yield, Landraces

\section{INTRODUCTION}

Germplasm diversity is a key for successful genetic improvement of plants. There must be phenotypic and genetic variability among the material targeted to be improved. Several studies have been undertaken to assess the variability among the accessions of sorghum. In Ethiopia Adugna (2014) found that there's a huge variability among farmers varieties. Shehzad and Okuno (2014) highlighted the necessity of diversity among sorghum varieties for the crop improvement. In Niger, the variability among sorghum accessions were revealed by (Deu et al., 2008). In a survey in Kenya Labeyrie et al. (2015) revealed the diversity among farmers varieties. Genetic diversity was found sorghum germplasm from Senegal (Tovignan et al., 
2015). In Burkina Faso, Barro-Kondombo (2010) found genetic diversity among sorghum accessions of three regions: Centre North, Centre West and Boucle du Mouhoun. The diversity among the farmers sorghum landraces was assessed by Ouedraogo (2015) for drought tolerant varieties. More recently, genetic diversity was found by Nerbewende et al. (2018) among sweet sorghum accessions collected in Burkina Faso. In fact, the germplasm collected was composed only of farmers' varieties. Most of the variability of sorghum comes from the open pollinated varieties possessed by farmers. Those differ from the improved varieties that have been purified and stabilized. There is a need to assess the genetic diversity to maintain and protect from genetic erosion. Several methods have been used to assess the genetic variability within sorghum populations around the world. This began with the crop's discovery and propagation. The phenotypic differences have been evaluated through several different methods. Molecular tools have been used to assess the diversity among the accessions with different agro-morphological traits at the genetic level. The assessment of the genetic variability could be useful to take into account the needs of the stakeholders involved in sorghum production improvement in Burkina Faso (Zongo et al., 2005). Several breeding programs on sorghum improvement around the world have characterised sorghum genetic diversity and several traits have been assessed. Varieties have been differentiated based on agronomical and physiological traits that are economically relevant including yield $\mathrm{s}$, disease resistance, insect tolerance; weed tolerances, mineral deficiencies, toxicities tolerances, and extreme weather tolerances of wheat, maize, rice, sorghum, potatoes, tomatoes, eggplants, cotton, peanuts, soybeans, and beans.

The objective of this work was to determine the genetic differences among improved varieties from researches centres and farmer accessions of Burkina Faso.

\section{MATERIALS AND METHODS \\ Germplasm Collection}

One hundred and twenty sorghum accessions obtained from farmers and Research centres were used in this study. Ninety-two accessions were collected during a participatory rural appraisal from farmers surveyed from different sites across the three agro-ecological zone of the country and from the main areas were sorghum is the major source of food (Figure 1). To avoid mixture and confounding of the farmer varieties, only panicles samples were collected from farmers and samples seeds were labelled according to their zones of provenance. Twenty-eight improved varieties were provided by Institute of Environment and Researches Agriculture (INERA) in Burkina Faso, International Crops Research Institute for the Semi-Arid Tropics (ICRISAT) Mali, IER (Institute of Economy Rural) in Mali, and Texas A\&M University.

\section{Molecular characterisation of sorghum germplasm}

The modified extraction buffer of Gawel and Jarret (1991) Mixed

alkyltrimethylammonium bromide (MATAB) was used to obtain purified DNA from one hundred and ten (110) sorghum seedlings from fifteen days old leaf samples. The DNA samples (110) were genotyped using a multiplexed complex of 28 microsatellites DNA markers. These markers have been used before to genotype a set of 3367 accessions of sorghum (Ramu et al., 2013; Billot et al., 2013). Various types of devices (laminar flow hood, centrifuges, thermo agitator and thermo blender) were used to obtain and homogenize the working solutions. Four types of thermocyclers were run for polymerization. The sequencer 24 capillaries $\mathrm{ABI}$ version $3500 \mathrm{XL}$ were used to sequence each allele that 
was amplified during the polymerase chain reaction.

\section{Data collection and analysis}

Molecular data were collected from the DNA of the accessions and an analysis of Genetic structure of the germplasm was obtained through the software Structure version (2.3.4). Genetic parameters were obtained through FSAT version (2.9.3.2) and Genetix version (4.0.5.2) that indicate the richness of the allelic and the genetic diversity index. PCA analysis and phylogenetic trees were done with DARWIN version (6). The genetic indices (observed and expected heterozygosity) of Hardy Weinberg Ho, He, FST, FIS, RS A, FIT, (Cockerham and Weir 1984) were used to estimate the linkage among the markers. The PIC value for each locus was computed based on the formula of (Smith et al., 1997). This value provides the discrimination power of a locus on the basis of the expressed number of alleles and the frequencies of the alleles present at the locus.

$\mathrm{PIC}=1-\sum_{i}^{n} f i^{2}$

$\mathrm{PIC}=$ polymorphic information content in which:

$F_{i}=$ frequency of the $\mathrm{i}^{\text {th }}$ allele in the analyzed sorghum accessions.

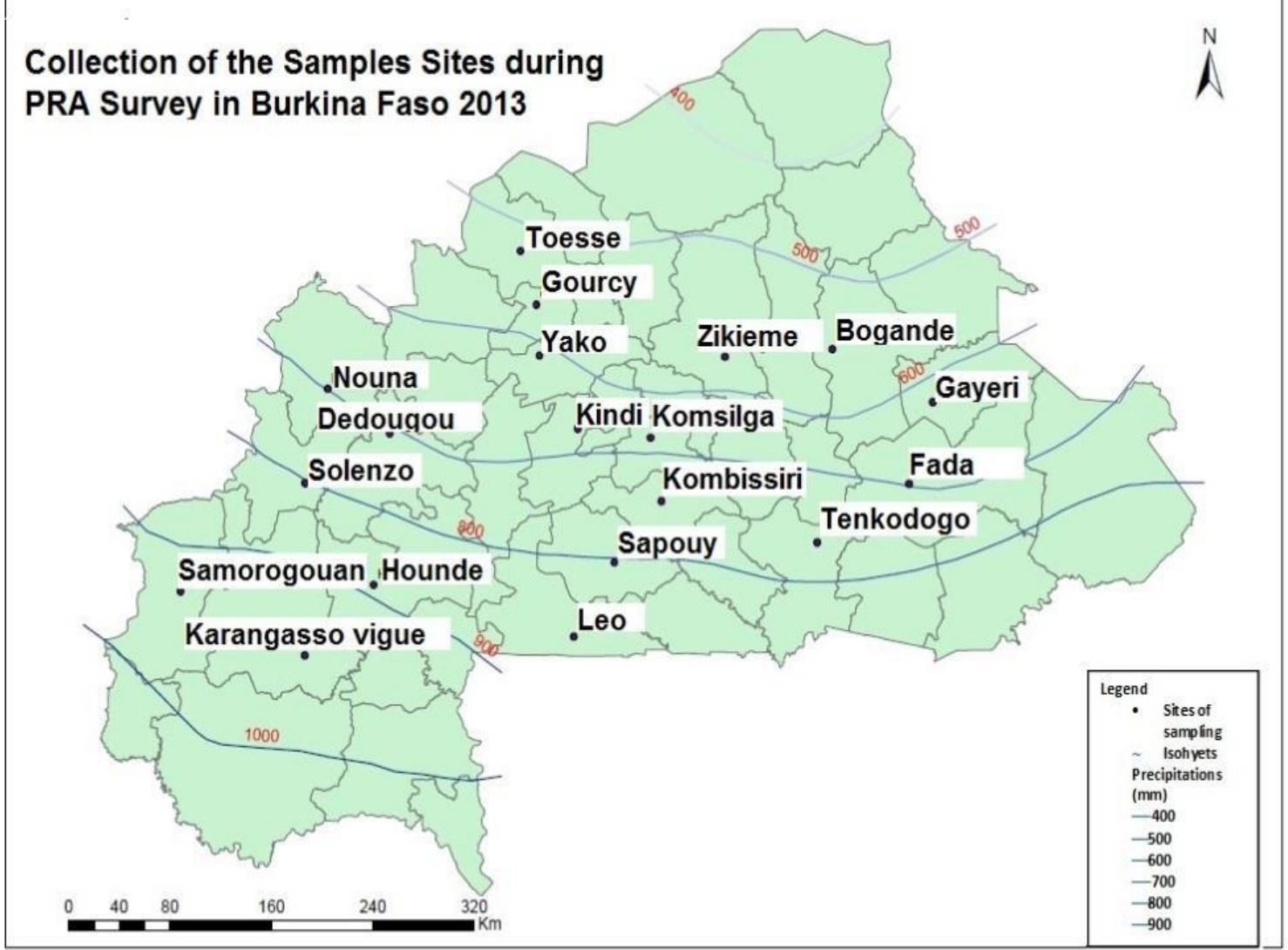

Figure 1: Sites where sorghum samples were collected during PRA Survey in Burkina 2013. 


\section{RESULTS}

\section{Molecular characterization of the sorghum germplasm \\ Genetic distance diversity parameters of the genotypes analysed}

From the diversity analysis, a total of 150 alleles were detected from the 28 SSR markers (Table 1). The allele size ranged from 96 SBAGB 02 (96-118) to 298 Gpsb 123 (286298). The number of alleles per locus varied from 2 (Xtxp 136, XCup 62, XCup 63, XCup $61 \mathrm{Gpsb} 148$ ) to 19 (Xtxp 295). The values of heterozygosity Ho $0<$ Hobs $>0.18$ were very low while the expected heterozygosity value was $0.02<\mathrm{He}>0.82$. Among the 28 loci analysed, 12 loci were highly polymorphic with a polymorphic information content $\mathrm{PIC} \geq$ 50\% (Xtxp 295, Gpsb 151, Xtxp 57, Xcup 07, Xcup 02, Xtxp 145, Xtxp 40, Gpsb 089, Xtxp 15, Gpsb 067, Sb5-206, and Gpsb 148). This value provides the discriminating power of a locus on the basis of the expressed number of alleles and the frequencies of generated alleles at each locus.

The genetic diversity parameters values were obtained by the software FSTAT version 2.9.3.2 and Genetix version 4.0.5.2. Among the 28 loci tested, a total 150 alleles were identified. Twenty-five of 28 markers scored alleles.

Loci analysis matrix from Darwin software version 6.012 shows that the accessions collected in different years and from different farming areas were genetically different. The time of cultivation of accessions by the farmers varies from five years to more than twenty years. The pink dots were illustrating the accessions that had been cultivated during the last five years the blue dots were for the varieties cultivated for about ten years, the brown dots were the varieties cultivated for about twenty years and the black illustrated the accessions cultivated more than twenty years of acquirement (Figure 2). The right side of the biplot showed more of the pink coloured dots; this was representing the improved varieties analysed while the left side of the biplot show a mixture of the varieties this was representing the farmers' varieties.

\section{Structure analysis of the sorghum accessions}

The software STRUCTURE version 2.3.4 by Pritchard et al. (2000) and Falush et al. (2003) was used to study the genetic structure of the 110 accessions of sorghum with the run parameters of 100000 Burn-in periods, 500000 iterations, and the $\mathrm{K}$ values varying from 1 to 10. $\mathrm{K}$ represents the hypothetical groups of individuals that composed the full accessions. The Figure 3 shows the truncation of the $\mathrm{k}$ value of 3. That was the best estimates of the hypothetical number of the individuals genotyped to the three groups. The groupings were based on the groups of sorghum races previously described by the research stations' varieties.

The genetic diversity indices at $\mathrm{K}$ value equal 3 suggest a high index of differentiation among families (FST) value between the groups. The mean value of the FST for the group1 was 0.5133 ; the FST for the group2 was 0.3358 and the FST for the group3 was 0.785 . The defined race groups were Guinea, Caudaum and Guinea-Caudatum (Figure 4. and Figure 5).

\section{Genetic indices based on structure of the groups of sorghum accessions}

The data show high value of inbreeding for all the accessions (FIT) $(0.80<$ FIT $>0.83)$

as well as for the value of the inbreeding level (FIS) within groups $(0.80<$ FIS $>0.83)$ (Table 2). The genetic diversity index, FST value, varied between $0<$ FST $>1$ which shows the genetic diversity among the groups of populations was not high. The values of Fit vary from $-1<$ FIT $>1$ which shows the level of inbreeding within samples at the population level whereas the FIS that varied between -1 $<$ FIS $>1$, showing the level of inbreeding in each group of the accessions Only a few groups had significant FST values at $\mathrm{P}<0.05$. The groups based on region had an overall FST $=$ 0.06. The groups based on Growth Cycle showed an FST $=0.02$ and the group based on Year of collection had an FST $=0.08$. 
Table 1: Genetic index estimation of 110 genotypes analysed with 28 SSR markers.

\begin{tabular}{|c|c|c|c|c|c|c|}
\hline Locus & Allele size & $\mathbf{A}$ & Rs & Ho & $\mathbf{H e}$ & PIC \\
\hline Gpsb067 & $170-186$ & 8 & 7.91 & 0.06 & 0.48 & 0.47 \\
\hline Gpsb089 & $165-173$ & 4 & 4.00 & 0.10 & 0.56 & 0.55 \\
\hline Gpsb123 & $286-298$ & 5 & 4.95 & 0.02 & 0.29 & 0.29 \\
\hline Gpsb148 & $135-143$ & 2 & 2.00 & 0.12 & 0.46 & 0.46 \\
\hline Gpsb151 & $104-130$ & 8 & 8.00 & 0.15 & 0.76 & 0.76 \\
\hline sb4-72 & $181-195$ & 5 & 5.00 & 0.08 & 0.39 & 0.39 \\
\hline Sb5-206 & $108-150$ & 10 & 9.99 & 0.03 & 0.48 & 0.47 \\
\hline Sb6-84 & $181-195$ & 4 & 4.00 & 0.05 & 0.39 & 0.39 \\
\hline SbAGB02 & $96-118$ & 6 & 5.99 & 0.03 & 0.31 & 0.31 \\
\hline Xcup02 & $192-204$ & 5 & 4.96 & 0.18 & 0.67 & 0.66 \\
\hline Xcup07 & $254-272$ & 6 & 6.00 & 0.12 & 0.68 & 0.67 \\
\hline XCup11 & $165-172$ & 2 & 2.00 & 0.00 & 0.25 & 0.25 \\
\hline XCup14 & $209-233$ & 5 & 5.00 & 0.07 & 0.44 & 0.43 \\
\hline Xcup53 & 186-198 & 4 & 4.00 & 0.07 & 0.35 & 0.35 \\
\hline XCup61 & $198-201$ & 2 & 2.00 & 0.12 & 0.37 & 0.37 \\
\hline XCup62 & $187-190$ & 2 & 1.96 & 0.01 & 0.01 & 0.01 \\
\hline XCup63 & $139-145$ & 2 & 2.00 & 0.06 & 0.33 & 0.33 \\
\hline Xtxp10 & $135-151$ & 6 & 6.00 & 0.00 & 0.33 & 0.32 \\
\hline Xtxp114 & $211-217$ & 3 & 3.00 & 0.00 & 0.39 & 0.38 \\
\hline Xtxp136 & $240-243$ & 2 & 2.00 & 0.00 & 0.02 & 0.02 \\
\hline Xtxp145 & $208-244$ & 7 & 7.00 & 0.14 & 0.61 & 0.60 \\
\hline Xtxp15 & $201-215$ & 8 & 8.00 & 0.08 & 0.55 & 0.55 \\
\hline Xtxp278 & $243-252$ & 3 & 3.00 & 0.06 & 0.29 & 0.29 \\
\hline Xtxp289 & $266-296$ & 5 & 5.00 & 0.05 & 0.36 & 0.36 \\
\hline Xtxp295 & $161-201$ & 19 & 18.86 & 0.15 & 0.82 & 0.81 \\
\hline Xtxp320 & $263-284$ & 2 & 2.00 & 0.17 & 0.07 & 0.07 \\
\hline Xtxp40 & $135-138$ & 7 & 6.96 & 0.00 & 0.60 & 0.59 \\
\hline Xtxp57 & $228-255$ & 8 & 8.00 & 0.15 & 0.72 & 0.71 \\
\hline
\end{tabular}

Ho: Observed heterozygosity He: Expected heterozygosity (Gene diversity) Rs allele richness A: number of allele PIC: Polymorphic information Content. 


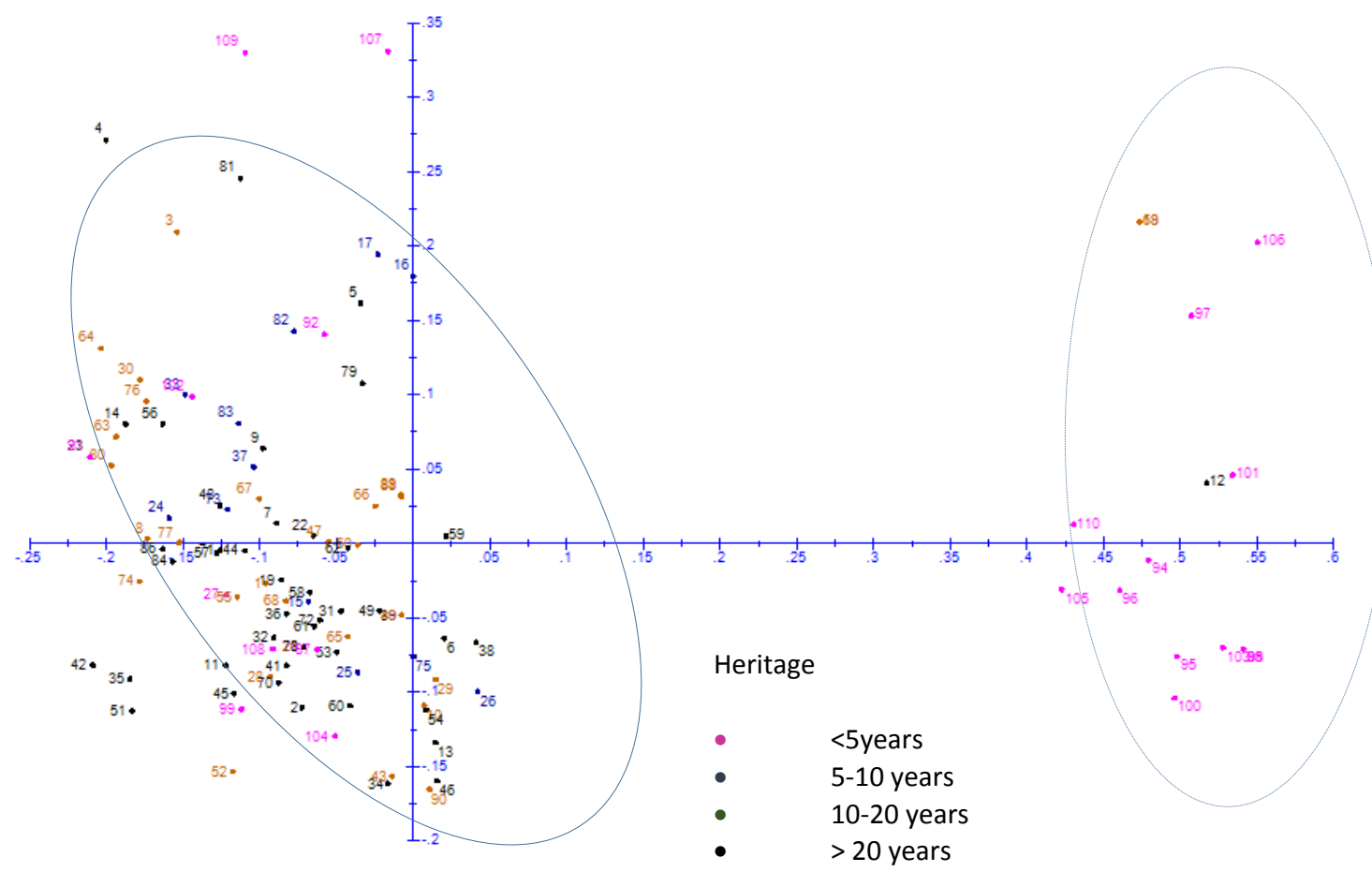

Figure 2: Principal coordinates analysis based on the dissimilarity index from the allelic data of the 28 microsatellites analyzed illustrating the years of acquirement of sorghum accessions.

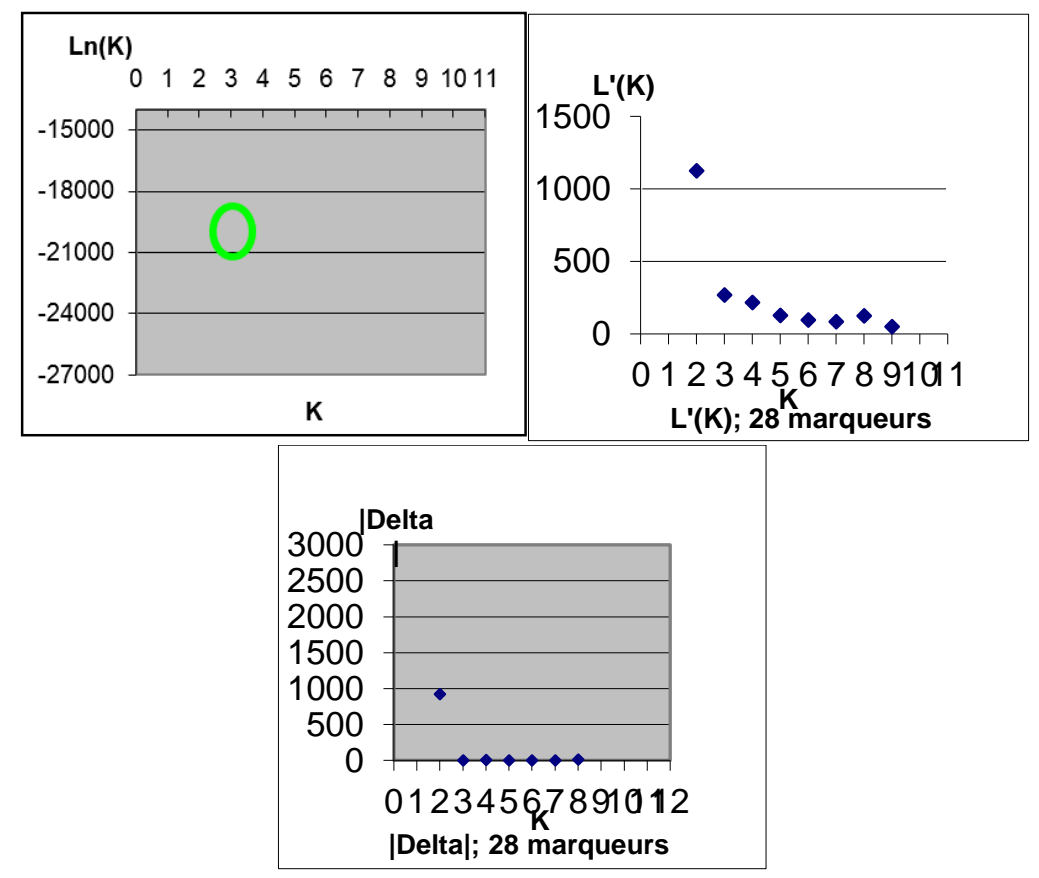

Figure 3: Number of groups of accessions described by the $\mathrm{K}$ value from the analysis runs with STRUCTURE 2.3.4. 


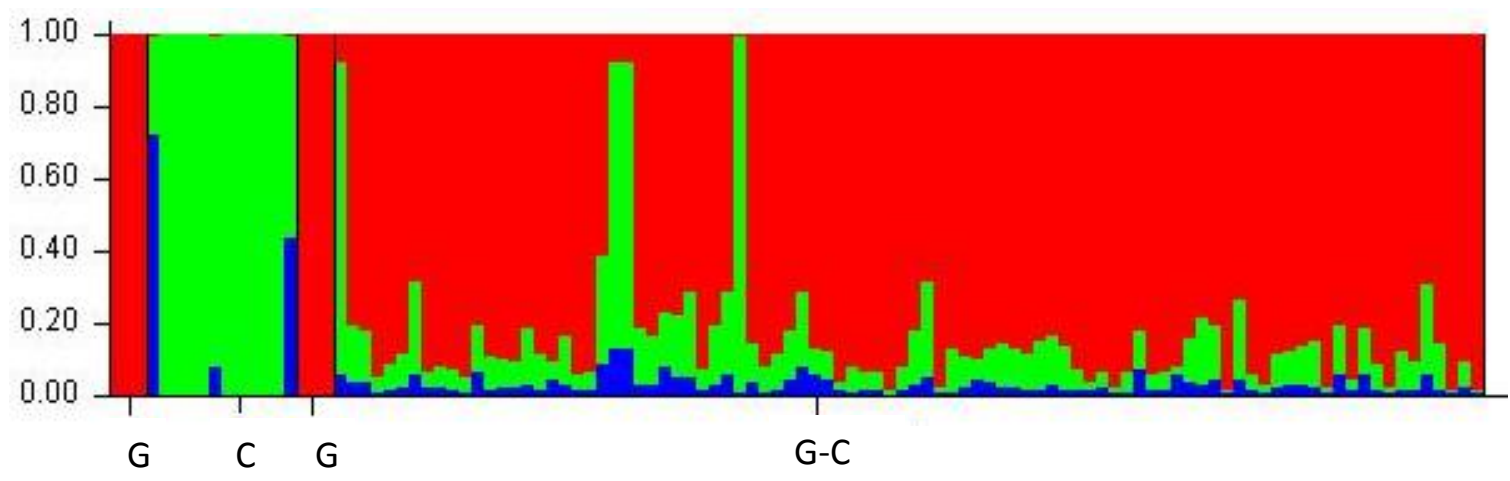

Figure 4: Diversity structure of a collection of sorghum accessions from Burkina Faso.

The full red is (G) the group of Guinea, the full green is (C) the group of Caudatum and the mixture of the red, green and blue is (G-C) the group of Guinea Caudatum according to the STRUCTURE program version 2.3.4 (Pritchard et al., 2000).

G

C

G

G-C
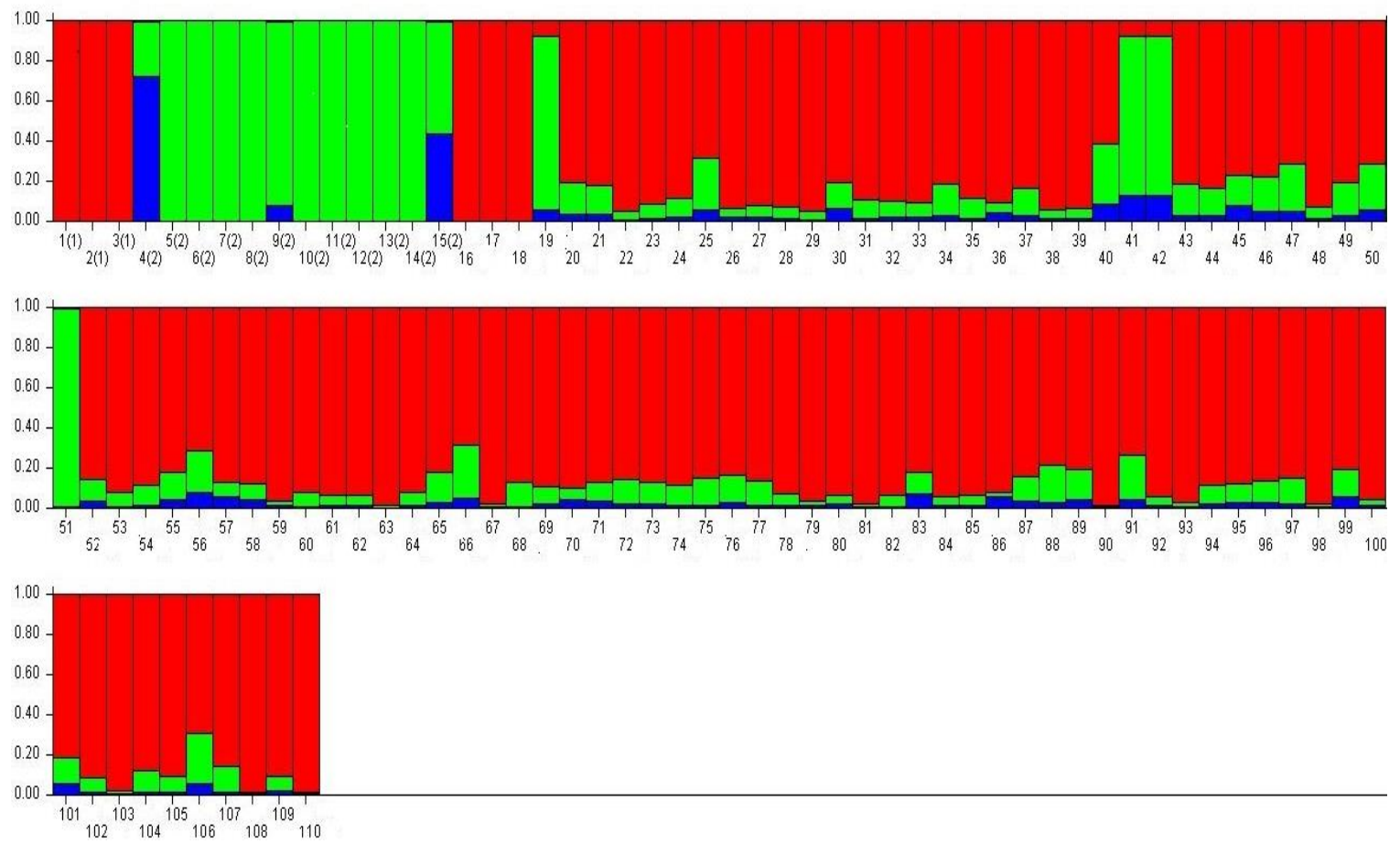

Figure 5: Relationship between the groups described by the STRUCTURE program and the sorghum accessions analyzed.

The full red is (G) the group of Guinea, the full green is (C) the group of Caudatum and the mixture of the red, green and blue is (G-C) the group of Guinea Caudatum according to the STRUCTURE program version 2.3.4 (Pritchard et al., 2000). 
Table 2: The genetic structure of the population of the accessions studied.

\begin{tabular}{|c|c|c|c|c|c|c|c|c|}
\hline Types of populations & $\mathbf{N}$ & $\mathbf{A}$ & Rs & Ho & He & Fst & FIS & FIT \\
\hline \multirow[t]{2}{*}{ Overall } & 110 & & & & & 0 & 0.83 & 0.83 \\
\hline & & 5.34 & 5.36 & 0.07 & 0.43 & & & \\
\hline Years of cultivation & 110 & & & & & $0.09 *$ & 0.82 & 0.83 \\
\hline$<5$ years & 24 & 4.04 & 3.53 & 0.03 & 0.53 & & & \\
\hline $5-10$ years & 12 & 3.86 & 2.82 & 0.12 & 0.37 & & & \\
\hline $10-20$ years & 28 & 3.50 & 2.89 & 0.09 & 0.36 & & & \\
\hline$>20$ years & 46 & 2.57 & 2.52 & 0.08 & 0.35 & & & \\
\hline Maturity cycle & 110 & & & & & $0.02 * *$ & 0.83 & 0.83 \\
\hline Average & 71 & 4.57 & 89.73 & 3.20 & 0.42 & & & \\
\hline Long & 28 & 3.68 & 81.91 & 2.93 & 0.36 & & & \\
\hline Short & 11 & 3.21 & 89.82 & 3.21 & 0.51 & & & \\
\hline Sources of varieties of seed & 110 & & & & & 0.16 & 0.81 & 0.84 \\
\hline Gift & 7 & 1.96 & 1.95 & 0.03 & 0.32 & & & \\
\hline INERA & 20 & 3.96 & 3.20 & 0.04 & 0.54 & & & \\
\hline Inherited & 83 & 4.32 & 2.53 & 0.36 & 0.09 & & & \\
\hline Local and improved & 110 & & & & & 0.20 & 0.81 & 0.85 \\
\hline Local accessions & 90 & 4.39 & 3.37 & 0.08 & 0.36 & & & \\
\hline Improved accessions & 20 & 3.96 & 3.92 & 0.04 & 0.54 & & & \\
\hline Populations Anthracnose Resistance & 110 & & & & & 0.12 & 0.81 & 0.84 \\
\hline Middle Resistant & 42 & 3.93 & 3.11 & 0.09 & 0.39 & & & \\
\hline Resistant & 12 & 3.14 & 3.14 & 0.01 & 0.46 & & & \\
\hline Susceptible & 56 & 4.43 & 3.12 & 0.08 & 0.37 & & & \\
\hline Populations Number of Internode & 110 & & & & & 0.15 & 0.81 & 0.84 \\
\hline High number & 64 & 3.82 & 2.92 & 0.07 & 0.33 & & & \\
\hline Middle number & 29 & 3.71 & 3.42 & & & & & \\
\hline Short number & 17 & 3.82 & 3.81 & & & & & \\
\hline Populations Sorghum race & 110 & & & & & 0.31 & 0.79 & 0.85 \\
\hline Caudatum & 16 & 3.11 & 3.10 & 0.03 & 0.40 & & & \\
\hline Guinea & 22 & 2.21 & 2.16 & 0.04 & 0.27 & & & \\
\hline Guinea-Caudatum & 72 & 3.82 & 3.02 & 0.09 & 0.35 & & & \\
\hline Populations Region & 110 & & & & & $0.06 *$ & 0.82 & 0.83 \\
\hline Boucle du Mouhoun & 19 & 3.21 & 2.40 & 0.08 & 0.38 & & & \\
\hline Centre & 12 & 3.46 & 2.93 & 0.06 & 0.50 & & & \\
\hline Centre-Est & 5 & 1.93 & 1.93 & 0.16 & 0.31 & & & \\
\hline Centre-Nord & 10 & 2.14 & 1.97 & 0.11 & 0.31 & & & \\
\hline Centre-Ouest & 10 & 2.00 & 1.83 & 0.03 & 0.25 & & & \\
\hline Est & 10 & 2.46 & 2.15 & 0.08 & 0.34 & & & \\
\hline Haut-Bassin & 29 & 3.96 & 2.79 & 0.05 & 0.50 & & & \\
\hline Nord & 15 & 2.82 & 2.23 & 0.09 & 0.33 & & & \\
\hline
\end{tabular}

*Significance at $\mathrm{p}<0.05 \mathrm{~N}=$ Number of varieties $\mathrm{A}=$ Allele diversity / the mean of Allele per locus Rs= the richness of the alleles $\mathrm{Ho}=$ heterozygosity observed $\mathrm{He}=$ heterozygosity expected. 


\section{DISCUSSION}

The genomic diversity study of the Burkina Faso accessions with the 28 SSRs markers showed that the lines were genetically diverse and the total number of alleles found was 150 which is similar to the total number of alleles (143 alleles) found by Barro-Kondombo et al. (2010) with 29 loci used. The markers results showed a wide range of PIC -0.01 to 0.81 . The low values reveal that some of the markers have a very low power of discrimination. The low polymorphic information content values were related to at least three loci, Xcup 62, Xcup11, Xtxp 40 and Xtxp 136. The low values of the Xcup loci are probably due to the fact that the markers were derived from expressed sequences tags (EST). The Xcup loci were found by sequences of genes that have been purified and sequenced. These markers do not vary much. Similar data were obtained by Barro-Kondombo et al. (2010), Mbeyagala et al. (2012) and Catherine et al. (2016). The hypothetical $\mathrm{K}$ value obtained showed the three clusters in which the lines were embedded. The three clusters were races Caudatum, Guinea and their intermediate, Guinea-Caudatum. The results are similar to the data obtained by Deu et al. (2008) on the diversity among Niger sorghum races. Barro-Kondombo et al. (2010) found similar results with landraces in Burkina Faso. In fact, the genetic structure distribution of the genotypes obtained by Barro-Kondombo et al. (2010) from farmers' landraces was three races. The highest race found was the Guinea race $(75 \%)$ and its different sections. The Bicolor rate was very low, while Caudatum race was not found. The similarities in the data may indicate the distribution of the same sorghum varieties in Africa mainly in West sub-Saharan zones. That is also acknowledged by Huckabay (1967) and de Wet (1978) where by the countries that share similar climate may share the same varieties across the countries' boundaries.

Overall, the data showed a lower level of observed heterozygosity of Ho $\leq 0.07$. This value suggests that the population studied was fairly homogeneous. Similar data was observed elsewhere (Deu et al., 2008; Barro-Kondombo et al., 2010). This reflects the inbreeding nature of the sorghum varieties in which the percentage of outcrossing in lower than 30\% (Reddy et al., 2008). This is consistent with the mean value of the FIT $=0.83$ and FIS $=0.83$. The FIT parameter represents the inbreeding level for a given population while the FIS represents the inbreeding level within the population (Cockerham and Weir, 1984). For sorghum varieties, the inbreeding indices values are generally high (Zongo et al., 2005). Similar results were also observed in other selfpollinated crops like Phaseolus lunatus L. or Lima beans (Ouedraogo et al., 2005). The overall mean value of the expected heterozygosity was low $\mathrm{He} \leq 0.45$. This suggests that due to the fact that sorghum is a self-pollinated, one should not expect to see a high level of heterozygosity within groups of sorghum. Similar of low heterozygosity were found by (Deu et al., 2008; Barro-Kondombo et al. 2010; Mbeyagala, et al., 2012). The value the of diversity parameters FST values of Cockerman and Weir (1984) represents the genetic differentiation among the families was significant and the coefficient varied from 0 to 1 for the families that were having high genetic differences. The FST value from the families analysed were generally low. However, for the families of populations based on the years of acquisition of the seeds by the farmers; the growth cycle lengths, as well as the family of the regions have shown significant Fst value.

\section{Conclusion}

This study has identified several morphological groups that contain both farmers' accessions and the improved varieties. The imported germplasm has some similarities with some of the improved varieties released in the country. The evaluation of the agronomic traits showed that several sources of the germplasm collections overlap even though they were collected from different agro ecological zones. The varieties studied were generally tall, photoperiod sensitive, susceptible to disease and low yielding. Several groups of accessions (local and improved) have their origin among the basic races of sorghum, especially the Guinea, Caudatum and their 
intermediate Guinea-Caudatum race. The allelic analysis results suggest that there are some similarities among sorghum lines from Burkina Faso and other West African countries, Niger and Mali. The computed genetic parameters FIT (the inbreeding level for an overall population) and FIS (the inbreeding level within a given population) were very high. This is consistent with the selfpollinating nature of the sorghum crop.

\section{COMPETING INTERESTS}

The authors declare that they have no competing interests.

\section{AUTHORS' CONTRIBUTIONS}

JS and BO suggested the title of the manuscript. ZSN, VG, PBT SOK designed and performed the research. JS, BO, VG, PBT and SOK reviewed the draft manuscript. All the authors read and approved the final manuscript.

\section{ACKNOWLEDGMENTS}

This work will not have been done with the help of various resources persons and Institutions. We are embedded to the embassy the France in Burkina Faso represent body through SCAC fellowship for the stay in France and the laboratory expenses and to the West African Center for Crop Improvement (WACCI) and our home Institute of Environment and Researches in Agriculture (INERA).

\section{REFERENCES}

Adugna A. 2014. Analysis of in situ diversity and population structure in Ethiopian cultivated Sorghum bicolor (L.) landraces using phenotypic traits and SSR markers. SpringerPlus, 3(1): 212. DOI: https://doi.org/10.1186/2193-1801-3-212

Barro-Kondombo CP. 2010. Diversités agromorphologique et génétique de variétés locales de sorgho [Sorghum bicolor (L.) Moench] du Burkina Faso. Eléments pour la valorisation des ressources génétiques locales. $\mathrm{PhD}$ thesis. Universite de Ouagadougou. p.137

Barro-Kondombo C, Sagnard F, Chantereau J, Deu M, Goze E, Kirsten vom Brocke,
Durand P, Zongo JD. 2010. Genetic structure among sorghum landraces as revealed by morphological variation and microsatellite markers in three agroclimatic regions of Burkina Faso. Theor Appl Genet, 120: 1511-1523. DOI: https://doi.org/10.1007/s00122-0101272-2

Billot C, Ramu P, Bouchet S, Chantereau J, Deu M, Rivallan R, Hash CT. 2013. Massive Sorghum Collection Genotyped with SSR Markers to Enhance Use of Global Genetic Resources. PLosS one, 8(4): $1-16 . \quad$ DOI: http://doi.org/10.1371/journal.pone.0059 714

Catherine WM, Reuben MM, Duncan T K, Steven M R, Arthur K. 2016. Genetic variability of sorghum landraces from lower Eastern Kenya based on simple sequence repeats (SSRs) markers. African Journal of Biotechnology, 15(8): 264271.

DOI: https://doi.org/10.5897/AJB2015.14680

Cockerham C, Clark Weir BS. 1984. Estimating F-Statistics for the Analysis of Population Structure. Society for the Study of Evolution 38(6): 1358-1370. DOI: https://doi. org/10.2307/2408641

de Wet J M J. 1978. Systematics and Evolution of Sorghum Sect. Sorghum (Gramineae). American Journal of Botany, 65(4): 477484.

DOI: https://doi.org/10.2307/2442706

Deu M, Sagnard F, Chantereau J, Calatayud C, Hérault D, Mariac C, Pham J L, Vigouroux Y, Kapran I, Traore P S, Mamadou A. 2008. Niger-wide assessment of in situ sorghum genetic diversity with microsatellite markers. Theoretical and Applied Genetics, 116(7): . 903-913. DOI: https://doi.org/10.1007/s00122-0080721-7

Falush D, Stephens M, Pritchard J K. 2003. Inference of population structure using multilocus genotype data: linked loci and correlated allele frequencies. Genetics, 164(4): $\quad 1567-$ $1587 . \quad$ DOI: 
https://doi.org/10.1111/j.14718286.2007. 01758.x

Gawel N L, Jarret R L A. 1991. Modified CTAB DNA extraction procedure of Musa and Ipomoea. Plant Molecular Biology Reporter, 9: 262-266. DOI; https://doi.org/10.1007/BF02672076

Huckabay J M, de Wet J P. 1967. The origin of Sorghum bicolor. II. Distribution and Domestication. Society for the Study of Evolution, 21(4): 782-802. DOI: 10.1111/j.1558-5646.1967.tb03434.x

Labeyrie V, Thomas M, Muthamia Z, Leclerc C. 2015. Seed exchange networks, ethnicity, and sorghum diversity. Proceedings of the National Academy of Sciences, 113(1): 98-103. DOI: https://doi.org/10.1073/pnas.1513238112 Mbeyagala E K, Kiambi D D, Okori P, Edema R. 2012. Molecular Diversity among Sorghum (Sorghum bicolor (L.) Moench) Landraces in Uganda. International Journal of Botany, 8(3): 85-95. DOI; http://dx.doi.org/10.3923/ijb.2012.85.95

Nerbewende S, Teyoure BJ, Zakaria K, Mahamadi HO, Wend-Pagnangde MS, Kiswendsida RN, Nebié B, Pauline BK, Renan ET, Mahamadou S, Jean-Didier Z. 2018. Assessment of genetic diversity of Burkina Faso sweet grain sorghum using microsatellite markers. African Journal of Biotechnology, 17(12): 389-395. DOI: https://doi.org/10.5897/AJB2017.16344

Ouedraogo N. 2015. Genetic Improvement of Local Sorghum (Sorghum bicolor L. Moench) Varieties for Drought Tolerance. PhD Thesis University of Ghana, Legon Accra p.165.

Pritchard JK, Matthew S, Donnelly P. 2000. Inference of Population Structure Using Multilocus Genotype Data. GENETICS, 155 (2): 945-959. DOI: https://doi: 10.1534/genetics.116.195164

Ramu P, Billot C, Rami JF, Senthilvel S,
Upadhyaya HD, Reddy AL, Hash CT. 2013. Assessment of genetic diversity in the sorghum reference set using EST-SSR markers. Theoretical and Applied Genetics, 126(8): 2051-2064. DOI: http://doi.org/10.1007/s00122-013-21176

Reddy BVS, Ramesh S, Ashok KA, Gowda CLL. 2008. Sorghum Improvement in the New Millennium. ( $1^{\text {st }}$ edn) Patancheru 502 324, Andhra Pradesh, India. International Crops Research Institute for the Semi-Arid Tropics. 340.

Shehzad T, Okuno K. 2014. Diversity assessment of sorghum germplasm and its utilization in genetic analysis of quantitative traits-A review. Australian Journal of Crop Science, 8(6): 937. DOI: https://doi.org/10.1007/s00122-0132117-6

Smith JSC, Chin ECL, Shu H, Smith OS, Wall SJ, Senior ML, Mitchell SE, Kresovich S, Ziegle J. 1997. An evaluation of the utility of SSR loci as molecular markers in maize (Zea mays L.): comparisons with data from RFLPs and pedigree. Theor Appl Genet, 95: 163-173. DOI: https://doi.org/10.1007/s001220050544

Tovignan TK, Luquet D, Fonceka D, Ndoye, Trouche G, Cisse N. 2015. Assessment of the variability of Senegalese landraces for phenology and sugar yield components to broaden the genetic pool of multi-purpose sorghum. Plant Genetic Resources, 14(2): 121-131.

DOI: https://doi.org/10.1017/S1479262115000 155

Zongo JD, Gouyon PH, Sarr A, Sandmeier M. 2005. Genetic diversity and phylogenic relations among Sahelian sorghum accessions. Genetic Resources and Crop Evolution, 52(7): 869-878. DOI: https://doi.org/10.1007/s10722-0036091-8. 